\title{
Understanding Health Related Quality of Life in Hypertensive Patients: Interrogating Effect of Psychological and Environmental Factors
}

\author{
Manisha Saini ${ }^{1}$, Minakshi Rana ${ }^{1}$, Karun Bhatti ${ }^{2}$, Rina Das ${ }^{1, *}$, Dinesh Kumar Mehta ${ }^{1}$ \\ 'M.M. College of Pharmacy, Maharishi Markandeshwar ((Deemed to be University), Mullana, Ambala, Haryana, INDIA. \\ 2Department of Medicine, M.M. Institute of Medical Sciences and Research, Maharishi Markandeshwar (Deemed to be University), Mullana, Ambala, Haryana, INDIA.
}

\begin{abstract}
Background: Health-related quality of life has become an important aspect in the field of healthcare as an important outcome measure for chronic diseases like hypertension. Improvement in HRQoL have become a focal point in health research, with clinicians, scientists and policy makers realizing the value of individual's self-rated experience, beyond or in addition to objective and clinical measure of health. Aim: To study the effect of psychological and environmental factors on $\mathrm{HRQOL}$ in patients suffering from hypertension using WHOOOLBREF questionnaire. Methods and Materials: The study was carried out for six weeks in medicine outpatient and inpatient department of a tertiary care hospital. All patients diagnosed with essential hypertension were recruited and socio-demographic and clinical data were noted. Patients were interviewed using WHOQOL-BREF using questionnaire. Results: Of total 100 patients, female was more prevalent to hypertension compared to male. Mean score of environmental domain was greater than the psychological domain [72.375 (SD \pm 19.23$)$ and 68.91667 (SD \pm 19.59 ), respectively] suggesting the inverse correlation of quality of life with negative thoughts, blue mood, anxiety and depression. Regarding individual questions, most of the participants felt safe in their
\end{abstract}

daily life, were satisfied with their physical environment and condition of living place with a mean score of $4.58(S D \pm 0.55), 4.03(S D \pm 0.69)$ and 4.24 $(\mathrm{SD} \pm 0.66)$, respectively. In contrary, majority of study participants often had negative feelings such as blue mood, anxiety, despair and depression [2.86 $(S D \pm 0.96)]$, were dissatisfied with their transport [3.5 $(S D \pm 0.85)]$ and lacked opportunity for leisure activities [3.57 ( $\mathrm{SD} \pm 0.85)]$ thus indicating poor quality of life as mean values were low. Conclusion: Female gender, older age, negative feelings, co-morbid condition and level of education may be important predictors of $\mathrm{QOL}$ in hypertensive patients.

Key words: Hypertension, Quality of life, WHO BREF QOL, Psychological factors, Environmental factors.

\section{Correspondence}

Dr. Rina Das,

Associate Professor, M.M. College of Pharmacy, Maharishi Markandeshwar (Deemed to be University), Mullana, Ambala, Haryana, INDIA.

Email id: rinammu@gmail.com

DOI: 10.5530/jyp.2022.14.19

\section{INTRODUCTION}

Blood Pressure is a condition in which the blood vessels have persistently raised arterial blood pressure and is the major risk factor for cardiovascular morbidity and mortality. ${ }^{1,2}$ World Health Organization has proclaimed hypertension as the global public health crises because of its high prevalence. ${ }^{1}$ Hypertension is classified as primary (essential) or secondary hypertension. ${ }^{3}$ Over $90 \%$ of individual has high blood pressure that results from unknown pathophysiologic etiology which is known as essential hypertension. Fewer than $10 \%$ of individual have secondary hypertension which is either due to a co- morbid disease or an effect of a drugs. ${ }^{4}$ Lifestyle factors that elevate the risk of high blood pressure includes stress, obesity, smoking, alcohol consumption, physical inactivity and excess salt intake in diet. ${ }^{5}$

One billion people are affected by hypertension globally worldwide and is cause of mortality, exceeding 10 million people per year. ${ }^{6}$ The prevalence and morbidity of hypertension is greater among older adults who often have multiple comorbidities. ${ }^{7}$ In the year 2000, 972 million people worldwide were living with hypertension. This number was predicted to increase by about $60 \%$ to a total of 1.56 billion by the year $2025 .^{8}$ It is one of the most controllable chronic conditions and adults with it are more likely to have other chronic condition. ${ }^{8}$ It was also ranked third as a cause of disability adjusted life years (DALYS) [8].

The Seventh Report of the Joint National Committee on Prevention, Detection, Evaluation and Treatment of High Blood Pressure (JNC-7 guidelines) has classified hypertension into following: ${ }^{9}$
- $\quad$ Normal BP: $<120 \mathrm{mmHg}$ and diastolic BP $<80 \mathrm{mmHg}$

- Prehypertension: SBP 120-139 mmHg or DBP 80-89 mmHg

- $\quad$ Stage 1 hypertension: SBP 140-159 mmHg or DBP 90-99 mmHg

- $\quad$ Stage 2 hypertension: SBP $\geq 160 \mathrm{mmHg}$ or DBP $\geq 100 \mathrm{mmHg}$

Rarely accompanied by symptoms, hypertension is generally identified while seeking medical care for any unrelated problem. People with hypertension have complaints of headache at back of the head, vertigo, lightheadedness, tinnitus, blurred vision, sweating, facial flushing and palpitations. ${ }^{10}$ Uncontrolled or poor management of hypertension results in serious complications like coronary heart disease, cerebrovascular disease, vision loss, peripheral arterial disease and renal insufficiency. ${ }^{11}$ To alleviate the risk of hypertension related cardiovascular disease, accurate measurement and recording of blood pressure is necessary which can be done either by Home Blood Pressure Monitoring (HBPM) or Ambulatory Blood pressure monitoring (ABPM). HBPM refers to the self-monitoring of blood pressure by the patients at home or outside clinic while ABPM refers to monitoring and recording of blood pressure at regular interval over a 24 -hr period. ${ }^{12}$ Diagnosis of hypertension also include assessment of target organ damage, cardiovascular risk and concomitant disease like diabetes mellitus, chronic kidney disease etc. that may affect blood pressure. ${ }^{13}$

For better management of hypertension and to abate the risk of cardiovascular disease or complication, lifestyle changes are 
recommended before initiating drug therapy. ${ }^{14}$ Lifestyle changes involves reduction in weight, decrease salt intake, increase in potassium rich food like banana, physical activity for at least half an hour per day, low fat diary food, reduce alcohol consumption and a healthy diet. Blood pressure medications are used when lifestyle changes are inadequate to control BP. ${ }^{14}$ Antihypertensive are class of drugs that are used to control hypertension. Various antihypertensive medications that control blood pressure by one or the other means includes Diuretics, ACE inhibitors, ARBs, beta blockers, Calcium channel blockers, alpha adrenergic blockers, vasodilators, and RAS antagonist. ${ }^{15}$

Health related quality of life (HRQoL) has become essential in clinical research over the past 15 years by providing a multidirectional outlook that incorporate patient's physical, social and emotional functioning which is related to individual's perception of the position in life that can be influenced by various factors such as physical health, social relationships, physiological state, and level of independence. ${ }^{16}$ Hypertension is closely linked to emotional and psychological problems that can affect health related quality of life of a person. ${ }^{17}$ Various study has indicated that hypertensive patients have lower quality of life when compared with normotensive people and is worse among those with a comorbid condition. ${ }^{18}$ Quality of life is an important measure to assess hypertensive treatment outcomes. ${ }^{19}$

World Health Organization with help of 15 collaborating factors around the globe constructed two tools for estimating quality of life of patients (WHOQOL-100 and WHOQOL-BREF). WHOQOL-100 consists of 100 questions that cover following dimension; physical health, level of independence, environmental, social and religious/spiritual/ personal belief. The WHOQOL-BREF questionnaire is a brief style of WHOQOL-100 is a cross cultural instrument that can cover broadly all features of quality of life including physical health, social, physiological and environmental. This psychometric tool was developed in year 1992. As WHOQOL-BREF doesn't impose any burden on the patient, so it can be useful instrument to assess HRQoL. ${ }^{20}$

The present study's overall goal is to study the effect of environmental and psychological factors on health-related quality of life of hypertensive patients.

\section{MATERIALS AND METHODS}

\section{Ethical Consideration}

The clinical protocol was approved by Institutional Ethics Committee (Project Number: IEC-1862 and Annexure No. I) on 22-1-2021. Informed consent was acquired from each participant before conducting the interview while confidentiality and privacy was ensured. Serial numbers were used on the questionnaire instead of the names of respondents in order to ensure confidentiality and this was maintained throughout and even after the study was completed. Respondents were adequately briefed about the right to refuse to participate or to withdraw from the study at any point in time. In addition, respondents were informed that refusal to participate in the study or withdrawal from it would not result in any loss of benefits or penalty. No patient was deprived of standard treatment during the duration study.

\section{Study Site}

After being approved by ethical committee, this hospital based observational study was carried out in Medicine ward and Out-patient Department of Maharishi Markandeshwar Institute of Medical Sciences and Research (MMIMSR), Mullana, Ambala, Haryana, India.

\section{Study Participants}

An observational study was conducted in MMIMSR, Mullana, Ambala. Patients diagnosed with hypertension by the physicians were recruited from OPD and IPD general medicine ward. All the patients were screened for eligibility of inclusion and exclusion criteria designed for the study. Patients with blood pressure $>140 / 90 \mathrm{mmHg}$ considered as hypertensive. All the patients were made aware about all the aspects and the purpose of the study in their native language prior to recruitment. Informed consent of the patients or their representative were taken by signing informed consent form. The study uses WHOQOL-BREF questionnaire that were marked by patients or their representative.

\section{Study Tools}

Sphygmomanometer (Atico sphygmomanometer) along with stethoscope was used to measure blood pressure of the patients. World health organization quality of life (WHOQOL) - BREF questionnaire was used to evaluate the health-related quality of life of hypertensive patients. Out of four domains, domains assessed were psychological (bodily image and appearance, negative feelings, positive feelings, selfesteem, spirituality / religion / personal beliefs, thinking, learning, memory and concentration) and environmental (financial resources, freedom, physical safety and security, health and social care: accessibility and quality, home environment, opportunities for acquiring new information and skills, participation in and opportunities for recreation / leisure activities, physical environment such as pollution / noise / traffic / climate; transport).

Study design: Hospital based observational study.

Study Duration: 6 months

Sample size: 100 participants

\section{Inclusion criteria}

- Patients' above 35 years of age with or without comorbidity.

- $\quad$ Both male and female patients.

- Patients able and willing to fill written informed consent to participate after full explanation of the study.

\section{Exclusion Criteria}

- Patients with significant disability (wheel chair user, mentally incompetent)

- Pregnant women

- Patients with pulmonary and portal hypertension are excluded.

- Patients with hypertensive emergency.

\section{Study Methodology (Figure 1)}

The auscultatory method of measuring the blood pressure was employed with the help of properly calibrated and validated with the help of Sphygmomanometer. Before the blood pressure measurement, the subject was seated for at least five minutes on a chair with feet on floor and arm floated at heart level. The systolic blood pressure was noted at the pressure point where the first heart sound was heard and the diastolic blood pressure was taken as the pressure at the point when the sound disappeared. To ensure the accuracy, two measurements were taken. Physician mentioned the blood pressure on the prescription and the patients were prescribed with antihypertensive drug as per requirement of the patients. Patients of age 35 and above and of either sex diagnosed with hypertension were included in the study. Recruited patients were informed about the study and its purpose in their vernacular language. Informed consent form was signed by all the patients and by their representatives. Demographics details of all the patients were recorded. Questionnaire was provided and completed by all the patients to assess their current health status. All the data was recorded, analyzed and kept confidential according to protocol guidelines. 


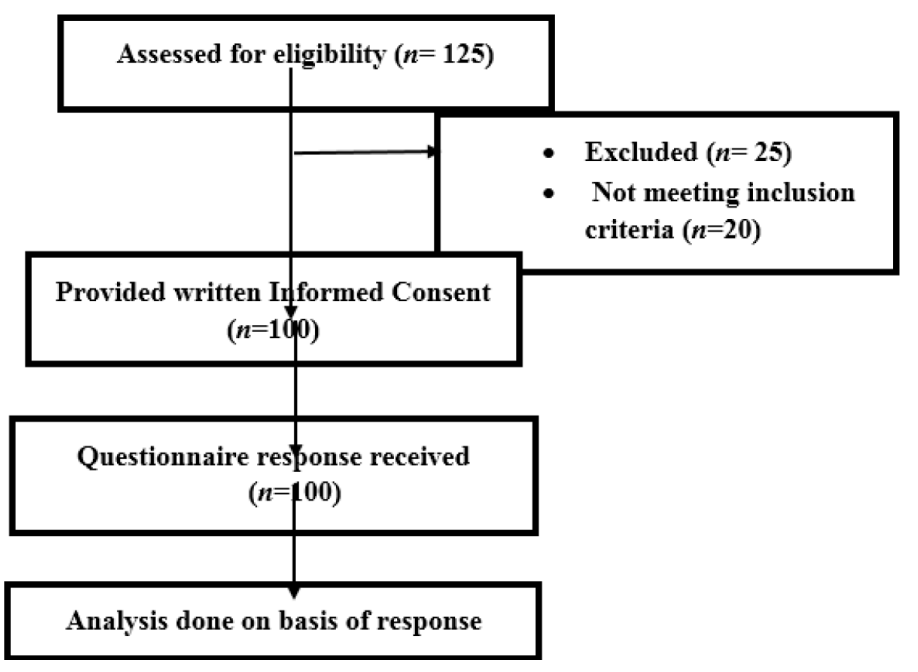

Figure 1: CONSORT flow diagram of the progress of the randomized trial.

\section{Statistical analysis}

The data obtained were entered, cleaned and analyzed. Descriptive data were presented using tables and charts.

\section{RESULTS}

The study was carried out to assess the impact of psychological and environmental factors on health-related quality of life of hypertensive patients.

The demographic of the patients (Table 1) indicated that hypertension was more prevalent in the female population (55\%) when compared to the male population (45\%). Data suggest that a greater number of patients were in between age group of 55-64 (32\%) followed by in age group of 65-74 (29\%). Least number of patients were observed in the age group of $75-85(1 \%)$. Out the 100 patients, $43 \%$ patients resided in rural area while $57 \%$ resided in urban area and shows that the highest proportion $21 \%$ and $35 \%$ of patients received primary and secondary education, respectively, while $32 \%$ of the patients had not received any formal education. Rest $9 \%$ and 3\% were university and post graduate respectively. During the study, from the sample of 100 patients, 54\% were housewife, $16 \%$ were employed outside the home, $12 \%, 10 \%$, and $6 \%$ were pensioner, farmer and wage earner respectively. Least number of patients have their own business (2\%). $26 \%$ of the patients had good health status while $57 \%, 15 \%$ and $2 \%$ had neither poor nor good, poor and very good health status respectively. In respect to pharmacotherapy, $36 \%$ patients were managed by single drug therapy while the others $64 \%$ were receiving a combination of two or three drug of different classes. Data also showed that $93 \%$ of the hypertensive patients were having multiple ailments while only $7 \%$ of the respondents were only hypertensive without any co-morbidity.

Psychological factors questionnaire response data (Figure 2) showed that and $56 \%$ of people relish their life very much. Only $12 \%$ of the patients enjoyed their life fully. Moderate response was given by $30 \%$ of people while least percent $(2 \%)$ of the patients enjoy their life a little. $18 \%, 59 \%$ and $23 \%$ patients felt their life moderately, very and extremely meaningful respectively. $20 \%$ and $47 \%$ of patients were able to concentrate extremely and very well while $30 \%$ of patients were moderately able to concentrate. Least percent of patients were able to concentrate a little (2\%) or not at all (1\%). Only $1 \%$ of patients were not able to accept their bodily appearance while $44 \%$ patient very much, $30 \%$ extremely and $25 \%$ moderately accepted their bodily appearance. $60 \%$ of
Table 1: Distribution of chart on hypertensive patients.

\begin{tabular}{|c|c|}
\hline Criteria & Percentage \\
\hline \multicolumn{2}{|l|}{ Gender } \\
\hline Male & $45 \%$ \\
\hline Female & $55 \%$ \\
\hline \multicolumn{2}{|l|}{ Age } \\
\hline $35-44$ & $15 \%$ \\
\hline $45-54$ & $23 \%$ \\
\hline $55-64$ & $32 \%$ \\
\hline $65-74$ & $29 \%$ \\
\hline $75-85$ & $1 \%$ \\
\hline \multicolumn{2}{|l|}{ Area } \\
\hline Rural & $43 \%$ \\
\hline Urban & $57 \%$ \\
\hline \multicolumn{2}{|l|}{ Level of Education } \\
\hline None & $32 \%$ \\
\hline Primary & $21 \%$ \\
\hline Secondary & $35 \%$ \\
\hline University & $9 \%$ \\
\hline Post graduate & $3 \%$ \\
\hline \multicolumn{2}{|l|}{ Occupation } \\
\hline Pensioner & $12 \%$ \\
\hline Wage earner & $6 \%$ \\
\hline Agriculture & $10 \%$ \\
\hline Business & $2 \%$ \\
\hline Service & $16 \%$ \\
\hline Housewife & $54 \%$ \\
\hline \multicolumn{2}{|l|}{ Health Status } \\
\hline Poor & $15 \%$ \\
\hline Neither poor not good & $57 \%$ \\
\hline Good & $26 \%$ \\
\hline Very good & $2 \%$ \\
\hline \multicolumn{2}{|l|}{ Drug Therapy } \\
\hline Single & $36 \%$ \\
\hline Combination & $64 \%$ \\
\hline \multicolumn{2}{|l|}{ Diagnosis } \\
\hline HTN & $7 \%$ \\
\hline HTN with comorbidity & $93 \%$ \\
\hline
\end{tabular}

patients were very well self-satisfied while $20 \%$ and $19 \%$ patients were extremely and moderately satisfied with themselves. Only $1 \%$ of patients were satisfied a little by themselves. Highest number of patients (43\%) moderately had feeling of blue mood, despair, anxiety or depression. $5 \%$ of the subjects had extreme negative feelings while $12 \%$ and $8 \%$ of participants felt depressed or anxious a little or not at all.

- Environment factors questionnaire response (Figure 3) indicates that $43 \%$ of patients felt moderately safe in everyday life whereas $32 \%, 12 \%$ and $8 \%$ of patients felt very much, a little and not at all safe, respectively. Only $5 \%$ patients felt extremely safe in their everyday life. $24 \%, 57 \%, 17 \%$ and $2 \%$ of subjects had extremely, very much, moderate and a little healthy physical environment, respectively. 
QUESTIONNAIRE RESPONSE OF PSYCHOLOGICAL FACTORS

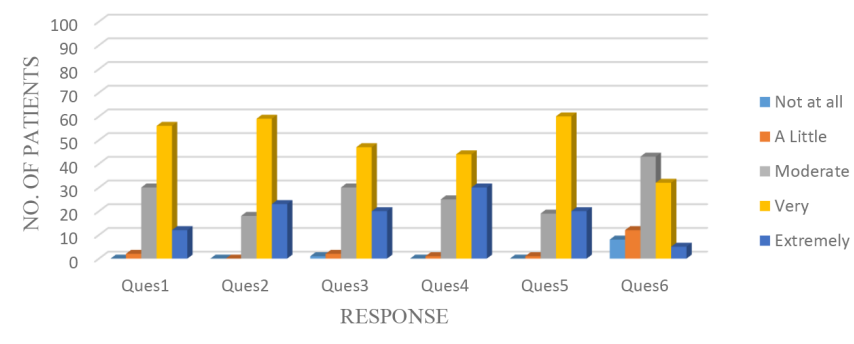

Figure 2: Psychological factors questionnaire response.

QUESTIONNAIRE RESPONSE OF ENVIRONMENTAL FACTORS

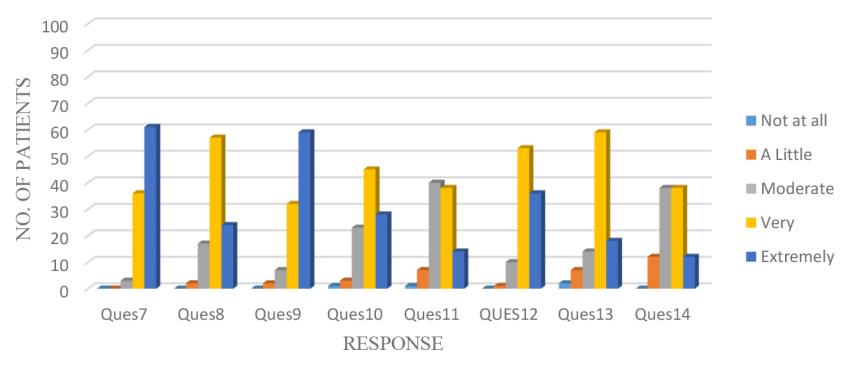

Figure 3: Environment factors questionnaire response.

Almost $59 \%$ of the participants had moderate financial condition while $32 \%$ and $7 \%$ patients had good and extremely well economic health. Only $2 \%$ of the people had financial trouble. $28 \%$ and $45 \%$ of subjects had mostly and completely information available needed in daily-to-daily life whereas $23 \%$ had moderately, $3 \%$ had a little and only $1 \%$ did not have any information available that is needed in day-to-day life. $40 \%$ and $38 \%$ of subjects had moderate and very much time or opportunity for leisure activities. Extremely, a little and not at all time for leisure activity was observed in 14\%, $7 \%$ and $1 \%$ of participants, respectively. $36 \%$ (extreme) and $53 \%$ (very much) patients were well satisfied by their living condition of living place while $10 \%$ patients were moderately satisfied only $1 \%$ patients were little satisfied with their living condition. $18 \%$ and $59 \%$ of participants were able to access the health services extremely and adequately. On the other hand, only $14 \%$ participants were able to access the health services moderately. Least percentage ( $7 \%$ and $2 \%)$ participants were not able to access the health services a little or not at all. 38\% patients were very and moderately and $12 \%$ were extremely and little satisfied with their transportation.

\section{DISCUSSION}

Hypertension is a major public health challenge worldwide..$^{21}$ Globally, one third of adult suffer from hypertension and half of the total death toll caused by cardiovascular diseases and cerebrovascular accident is due to hypertension. ${ }^{22}$ Hypertension is linked as most important predisposing factor for cardiovascular diseases and affect quality of life. ${ }^{22}$ People suffering from hypertension were found to have low health related quality of life compare with normotensive individuals. ${ }^{23}$ This study represented the health-related quality of life of hypertensive patients on the patients admitted in general medicine ward or attending the general outpatient's department at Maharishi Markandeshwar Institute of Medical Sciences and Research, Mullana, Ambala, Haryana. The present study was a hospital based prospective observational study carried out for a period of 6 months conducted by the means of WHOQOL-BREF questionnaire to assess the quality of life among patients.

Among total study respondent, 55\% of the study sample was female while $45 \%$ were male of which $32 \%$ belonged to $55-64$ years age group followed by $29 \%$ in $65-74$ years age group. Maximum number of patients belongs to urban area (57\%) and received secondary education (35\%) while $32 \%$ study respondent were illiterate and only $3 \%$ respondent were highly educated. $64 \%$ of the patients were receiving combination therapy and $52 \%$ of the study population had neither poor nor good health status. Our study showed higher prevalence of hypertension in female when compared to male population. Similar prevalence of hypertension among females were observed in the study conducted by Bhavit B Oza et al. ${ }^{24}$ High prevalence in females can be linked with decline in estrogen productions after age of 40 years and leading to arteriosclerosis.

Now-a-days, ameliorating the quality of life of the population have become an important goal for the healthcare professionals along with treating with illness. ${ }^{25}$ Health status and socioeconomic factors can influence quality of life of population on both individuals and community level. ${ }^{25}$ It has been noted that poor quality of life is associated with lack of financial resources, illiteracy and presence of comorbid condition ${ }^{26}$ This agree with our study where the better quality of life was observed among those who have attained better education [Table 2]. Previous studies and this study have revealed age and gender variation in the quality of life of hypertensive patients. Men and patients in younger age group had overall better quality of life and men scored slightly higher mean value in psychological domain indicating that men can endure chronic illness without being emotionally affected to the same extent as women [Table 2]. The study on the quality of life of patients with chronic conditions conducted by Stewart et al. showed that patients with multiple disorder manifested greater decline in functioning and well-being than those having single ailment. ${ }^{27}$ Hypertension is often accompanied by one or more comorbid condition thus leading to further deterioration of quality of life of hypertensive patients in all domains. Each additional disease exerts its burden on patient's physical functioning, restricting his/ her daily activities along with considerable consequences on emotional status. ${ }^{27}$ In our study comorbid condition were encountered among 93\% of our patients, thus suggesting further deterioration of quality of life in both domains.

There has always been an effort made through clinical trials to identify the superior antihypertensive drug over another in controlling blood pressure without impairing quality of life. ${ }^{28}$ Our study result showed that number of hypertensive drugs prescribed had no influence on quality of life of the study participants [Table 2]. Study conducted by Mclnnes GT ${ }^{29}$ pointed out that aggressive treatment with combinational therapy does not generally impair quality of life but various other studies showed the role of drug side-effect. ${ }^{28,29}$

Table 3 represents the mean score of the WHOQOL-BREF questionnaire among respondents. Mean score of environmental domain was greater than the psychological domain [72.375 (SD \pm 19.23 ) and 68.91667 ( $\mathrm{SD} \pm 19.59)$, respectively] suggesting the inverse correlation of quality of life with negative thoughts, blue mood, anxiety and depression. Regarding individual questions, most of the participants felt safe in their daily life, were satisfied with their physical environment and condition of living place with a mean score of 4.58 ( $\mathrm{SD} \pm 0.55), 4.03(\mathrm{SD} \pm 0.69)$ and 4.24 ( $\mathrm{SD} \pm 0.66)$, respectively. In contrast, majority of study participants often had negative feelings such as blue mood, anxiety, despair and depression [2.86 $(\mathrm{SD} \pm 0.96)]$, were dissatisfied with their transport [3.5 $(\mathrm{SD} \pm 0.85)]$ and lacked opportunity for leisure activities [3.57 $(\mathrm{SD} \pm 0.85)]$ thus indicating poor quality of life as mean values were low. 
Table 2: Comparison of HRQoL score among study population.

\begin{tabular}{|c|c|c|c|c|}
\hline \multicolumn{5}{|c|}{ Mean } \\
\hline Features & Psychological & Environmental & Total & SD \\
\hline \multicolumn{5}{|c|}{ Gender } \\
\hline Female & 3.618182 & 3.831818 & 14.96104 & 3.41967 \\
\hline Male & 3.925926 & 3.972222 & 15.80952 & 3.36283 \\
\hline \multicolumn{5}{|c|}{ Age } \\
\hline $35-44$ & 3.96667 & 3.95 & 15.82857 & 3.57143 \\
\hline $45-54$ & 3.76087 & 3.80978 & 15.15528 & 3.26323 \\
\hline $55-64$ & 3.70721 & 3.9527 & 15.38996 & 3.52257 \\
\hline $65-74$ & 3.74306 & 3.86979 & 15.2619 & 3.24564 \\
\hline $75-84$ & 2.66667 & 3.5 & 12.57143 & 3.45775 \\
\hline \multicolumn{5}{|c|}{ Place } \\
\hline Rural & 3.7481 & 3.8459 & 15.21595 & 3.32337 \\
\hline Urban & 3.7632 & 3.932 & 15.4386 & 3.48873 \\
\hline \multicolumn{5}{|c|}{ Education } \\
\hline None & 3.54167 & 3.82422 & 14.69167 & 3.40770 \\
\hline Primary & 3.81746 & 3.80357 & 15.02222 & 3.64108 \\
\hline Secondary & 3.80952 & 3.92857 & 15.31429 & 3.48857 \\
\hline University & 4.03704 & 4.125 & 16.05926 & 3.42022 \\
\hline Post Graduate & 4.1667 & 4.20833 & 16.53333 & 3.67794 \\
\hline \multicolumn{5}{|c|}{ Therapy } \\
\hline Single & 3.776 & 3.957 & 15.03175 & 3.47884 \\
\hline Combination & 3.7222 & 3.7847 & 15.51786 & 3.37452 \\
\hline
\end{tabular}

Table 3: Mean score of WHOQOL-BREF Questionnaire among study population.

\begin{tabular}{|c|c|c|c|}
\hline $\begin{array}{l}\text { Q } \\
\text { No. }\end{array}$ & Questions & Mean & SD \\
\hline 1 & How much do you enjoy life? & 3.78 & 0.67201 \\
\hline 2 & $\begin{array}{l}\text { To what extent do you feel your life to be } \\
\text { meaningful? }\end{array}$ & 4.05 & 0.63835 \\
\hline 3 & How well are you able to concentrate? & 3.83 & 0.80068 \\
\hline 4 & Are you able to accept your bodily appearance? & 4.03 & 0.76752 \\
\hline 5 & How satisfied are you with yourself? & 3.99 & 0.65566 \\
\hline 6 & $\begin{array}{l}\text { How often do you have negative feelings such } \\
\text { as blue mood, despair, anxiety, depression? }\end{array}$ & 2.86 & 0.96974 \\
\hline 7 & How safe do you feel in your daily life? & 4.58 & 0.55099 \\
\hline 8 & How healthy is your physical environment? & 4.03 & 0.69935 \\
\hline 9 & Have you enough money to meet your needs? & 3.44 & 0.65299 \\
\hline 10 & $\begin{array}{c}\text { How available to you is the information that } \\
\text { you need in your daily-to-day life? }\end{array}$ & 3.96 & 0.84758 \\
\hline 11 & $\begin{array}{c}\text { To what extent do you have the opportunity for } \\
\text { leisure activities? }\end{array}$ & 3.57 & 0.85152 \\
\hline 12 & $\begin{array}{c}\text { How satisfied are you with the condition of } \\
\text { your living place? }\end{array}$ & 4.24 & 0.66513 \\
\hline 13 & $\begin{array}{l}\text { How satisfied are you with your access to health } \\
\text { services? }\end{array}$ & 3.84 & 0.86856 \\
\hline \multirow[t]{3}{*}{14} & How satisfied are you with your transport? & 3.5 & 0.8544 \\
\hline & Environmental domain score & 72.375 & 19.7342 \\
\hline & Psychological domain score & 68.91667 & 19.5965 \\
\hline
\end{tabular}

This study provides an evaluation of HRQoL in representative sample of patients with hypertension. We examined the relationship of QoL to various sociodemographic, environmental and psychological factors. The strength of our study was the use of WHOQOL-BREF questionnaire to measure the quality of life which has proved acceptability, reliability and validity. But the limitation of this study was small sample size. As the sample size was small and the study was from single center for the analysis of HRQoL in hypertensive patients, the findings cannot be generalized. So, multi-centric studies with larger sample size are required in this direction.

\section{CONCLUSION}

Health-related quality of life has become an important aspect in the field of healthcare. Improvement in HRQoL have become a focal point in health research, with clinicians, scientists and policy makers realizing the value of individual's self-rated experience, beyond or in addition to objective and clinical measure of health. WHOQOL-BREF is a reliable tool in the measurement of HRQoL in hypertensive patients. The current study revealed that among the two domains of WHOQOLBREF i.e., environmental and psychological, environmental domain scored higher mean score than psychological domain indicating greater negative influence of negative feelings on the health-related quality of life of hypertensive patients. The study showed that female gender, older age, negative feelings, co-morbid condition and lack of education were negatively associated with the quality of life whereas male gender, young age, better education were positively correlated with better quality of life. Thus, all these factors are the important predictors of health-related quality of life in hypertensive patients.

\section{ACKNOWLEDGEMENT}

The authors wish to thank M.M. College of Pharmacy, Maharishi Markandeshwar (Deemed to be University), Mullana, India for all necessary facilities.

\section{CONFLICT OF INTEREST}

The authors declared no potential conflicts of interests with respect to the research, authorship, and/or publication of this article.

\section{REFERENCES}

1. Hypertension [internet]; 2021. Who.int [cited Jun 10 2021]. Available from: https://www.who.int/westernpacific/health-topics/hypertension.

2. Wu CY, Hu HY, Chou YJ, Huang N, Chou YC, Li CP. High blood pressure and All-Cause and cardiovascular disease mortalities in community-dwelling older adults. Medicine. 2015;94(47):e2160. doi: 10.1097/MD.0000000000002160, PMID 26632749.

3. Poulter NR, Prabhakaran D, Caulfield M. Hypertension. Lancet. 2015;386(9995):801-12. doi: 10.1016/S0140-6736(14)61468-9, PMID 25832858.

4. DiPiro JT, Talbert RL, Yee GC, Matzke GR, Wells BG, Posey LM, editors. Pharmacotherapy: a pathophysiologic approach. 10th ed. McGraw-Hill; 2017.

5. Kim IG, So WY, Sung DJ. The relationships between lifestyle factors and hypertension in community-dwelling Korean adults. J Phys Ther Sci. 2015;27(12):3689-92. doi: 10.1589/jpts.27.3689, PMID 26834333.

6. Lu Y, Yan H, Yang J, Liu J. Occupational stress and psychological health impact on hypertension of miners in noisy environment in Wulumuqi, China: A casecontrol study. BMC Public Health. 2020;20(1):1675. doi: 10.1186/s12889-02009760-9, PMID 33167970.

7. Adebusoye L, Ladipo M, Owoaje E, Ogunbode A. Morbidity pattern amongst elderly patients presenting at a primary care clinic in Nigeria. Afr J Prim Health Care Fam Med. 2011;3(1).

8. Kearney PM, Whelton M, Reynolds K, Muntner P,Whelton PK, He J. Global burden of hypertension: Analysis of worldwide data. Lancet. 2005;365(9455):217-23. doi: 10.1016/S0140-6736(05)17741-1, PMID 15652604.

9. Journal NEJM. Watch: Summaries of and commentary on original medical and scientific articles from key medical journals [internet]; 2021. Jwatch.org. [cited Jun 10 2021] Available from: https://www.jwatch.org/ jw200305300000001/2003/05/30/new-hypertension-guidelines-jnc-7.

10. Fauci AS, Braunwald E, Isselbacher KJ, Wilson JD, Martin JB, Kasper DL, et al., 
editors. Harrison's principles of internal medicine. $16^{\text {th }}$ ed. New York: McGrawHill. "Hypertensive vascular disease". p. 1463-81.

11. Drozdz D, Kawecka-Jaszcz K. Cardiovascular changes during chronic hypertensive states. Pediatr Nephrol. 2014;29(9):1507-16. doi: 10.1007/s00467013-2614-5, PMID 24026758.

12. Muntner P, Shimbo D, Carey RM, Charleston JB, Gaillard T, Misra S, et al. Measurement of blood pressure in humans: A scientific statement from the American Heart Association. Hypertension. 2019;73(5):e35-66. doi: 10.1161/ HYP.0000000000000087, PMID 30827125

13. Oparil S, Acelajado MC, Bakris GL, Berlowitz DR, Cífková R, Dominiczak AF, et al. Hypertension. Nat Rev Dis Primers. 2018;4(1):18014. doi: 10.1038/nrdp.2018.14, PMID 29565029.

14. Gupta R, Guptha S. Strategies for initial management of hypertension. Indian J Med Res. 2010;132:531-42. PMID 21150005.

15. Jackson R, Bellamy M. Antihypertensive drugs. BJA Educ. 2015;15(6):280-5. doi: 10.1093/bjaceaccp/mku061.

16. Tchicaya A, Lorentz N, Demarest S, Beissel J, Wagner DR. Relationship between self-reported weight change, educational status, and healthrelated quality of life in patients with diabetes in Luxembourg. Health Qual Life Outcomes. 2015;13(1):149. doi: 10.1186/s12955-015-0348-8, PMID 26385815.

17. Everson SA, Kaplan GA, Goldberg DE, Salonen JT. Hypertension incidence is predicted by high levels of hopelessness in Finnish men. Hypertension. 2000;35(2):561-7. doi: 10.1161/01.hyp.35.2.561, PMID 10679498.

18. Wang $R$, Zhao $Y, H e X, M a X$, Yan $X$, Sun $Y$, et al. Impact of hypertension on health-related quality of life in a population-based study in Shanghai, China. Public Health. 2009;123(8):534-9. doi: 10.1016/j.puhe.2009.06.009, PMID 19665154.

19. Ha NT, Duy HT, Le NH, Khanal V, Moorin R. Quality of life among people living with hypertension in a rural Vietnam community. BMC Public Health. 2014:14(1):833. doi: 10.1186/1471-2458-14-833, PMID 25113528.
20. WHOQOL-BREF. Introduction, administration, scoring and generic version of the assessment. Field trial version, December 1996.

21. Jayarajah U, Jayakody AJA, Jayaneth MBJN, Wijeratne S. Prevalence of hypertension and its associated factors among a group of bus drivers in Colombo, Sri Lanka. Int J Occup Environ Med 2017;8:58-59.

22. World Health Organization. World health Statistics 2012. Geneva: WHO; 2012.

23. Zhang L, Guo X, Zhang J, Chen X, Zhou C, Ge D, et al. Health-related quality of life among adults with and without hypertension: A population-based survey using EQ-5D in Shandong, China. Sci Rep. 2017;7(1):14960. doi: 10.1038/ s41598-017-15083-4. PMID 29097724.

24. Oza BB, Patel BM, Malhotra SD, Patel VJ. Health related quality of life in hypertensive patients in a tertiary care teaching hospital. J Assoc Physicians India. 2014;62(10):22-9. PMID 25906517.

25. Clark NM. Understanding individual and collective capacity to enhance quality of life. Health Educ Behav. 2000;27(6):699-707. doi: 10.1177/109019810002700606 PMID 11104370.

26. Youssef RM, Moubarak II, Kamel MI. Factors affecting the quality of life of hypertensive patients. East Mediterr Health J. 2005:11(1-2):109-18. PMID 16532679.

27. Stewart AL, Greenfield S, Hays RD, Wells K, Rogers WH, Berry SD, et al Functional status and well-being of patients with chronic conditions. Results from the medical Outcomes Study. JAMA. 1989;262(7):907-13. doi: 10.1001/ jama.1989.03430070055030, PMID 2754790

28. Anderson RB, Hollenberg NK, Williams GH. Physical Symptoms Distress Index: A sensitive tool to evaluate the impact of pharmacological agents on quality of life. Arch Intern Med. 1999;159(7):693-700. doi: 10.1001/archinte.159.7.693, PMID 10218748.

29. McInnes GT. Integrated approaches to management of hypertension: Promoting treatment acceptance. Am Heart J. 1999;138(3 Pt 2):252-5. doi: 10.1016/s0002 8703(99)70318-2, PMID 10467221.

Article History: Received: 04-10-2021; Revised: 23-11-2021; Accepted: 12-12-2021

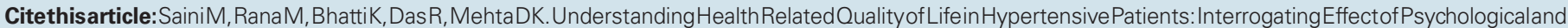
Environmental Factors. J Young Pharm. 2022;14(1):100-5. 